\title{
In situ photoelectron spectroscopy study of ethanol steam reforming over $\mathrm{RhPd}$ nanoparticles and $\mathrm{RhPd} / \mathrm{CeO}_{2}$
}

\begin{abstract}
Núria J. Divins and Jordi Llorca*
Institute of Energy Technologies and Centre for Research in Nanoengineering, Universitat Politècnica de Catalunya, Diagonal 647, ed. ETSEIB, 08028 Barcelona, Spain.
\end{abstract}

*Corresponding author:

Prof. Jordi Llorca

Institut de Tècniques Energètiques,

Universitat Politècnica de Catalunya

Av. Diagonal 647, Ed. ETSEIB

08028 Barcelona, Spain

Tel.: (+34) 934011708

Fax.: (+34) 934017149

e-mail: jordi.llorca@upc.edu 


\section{Abstract}

In situ X-ray photoelectron spectroscopy (XPS) was carried out over model $\mathrm{Rh}_{0.5} \mathrm{Pd}_{0.5}$ nanoparticles and $\mathrm{Rh}_{0.5} \mathrm{Pd}_{0.5}$ nanoparticles supported on $\mathrm{CeO}_{2}$ following exposure to oxygen at $573-823 \mathrm{~K}$, to hydrogen at $573 \mathrm{~K}$ (activation of the catalyst), to a mixture of ethanol and water at $823 \mathrm{~K}$ simulating ethanol steam reforming (ESR) conditions, and to hydrogen at $823 \mathrm{~K}$. The presence of the $\mathrm{CeO}_{2}$ support had a strong influence on the atomic rearrangement and on the oxidation state of $\mathrm{Rh}_{0.5} \mathrm{Pd}_{0.5}$ nanoparticles. Ceria exerted a quenching effect on the metal nanoparticles and inhibited atomic rearrangement under the different atmospheres tested except for ESR, where a partial segregation of $\mathrm{Rh}$ towards the surface of the nanoparticles was observed. When supported on $\mathrm{CeO}_{2}, \mathrm{Rh}_{0.5} \mathrm{Pd}_{0.5}$ nanoparticles were significantly more oxidized due to metal-support interaction. By comparing these in situ XPS results with a previous operando near-ambient pressure XPS study conducted in a synchrotron facility at 0.05 mbar over the same samples, it is concluded that the information obtained for the unsupported $\mathrm{Rh}_{0.5} \mathrm{Pd}_{0.5}$ nanoparticles is similar in both cases, whereas $\mathrm{Rh}_{0.5} \mathrm{Pd}_{0.5}$ nanoparticles supported on $\mathrm{CeO}_{2}$ are clearly more oxidized and enriched in $\mathrm{Pd}$ in the volume sampled under operando ESR conditions compared to that obtained in the in situ experiments. The study of catalytic systems under operando conditions appears essential to identify the active species at work during ESR, as the restructuring driven by the reforming environment induces strong changes in their architecture.

\section{Keywords}

XPS, ethanol steam reforming, hydrogen, ceria, bimetallic nanoparticles 


\section{Introduction}

The ethanol steam reforming (ESR, $\mathrm{C}_{2} \mathrm{H}_{5} \mathrm{OH}+3 \mathrm{H}_{2} \mathrm{O} \rightarrow 6 \mathrm{H}_{2}+2 \mathrm{CO}_{2}$ ) reaction is a well-known catalytic route for producing hydrogen from a renewable source (bioethanol) with low carbon impact. In addition to sustainability issues, bioethanol is a widespread substrate which is safe and easy to handle, and it has high hydrogen content. Numerous catalyst formulations have been tested so far for the ESR [1-5] and, among them, $\mathrm{RhPd} / \mathrm{CeO}_{2}$ has shown excellent performance in terms of activity and robustness [6]. This has been attributed to the cooperative effect of the carbon-carbon bond scission capabilities of $\mathrm{Rh}$, the hydrogen recombination ability of $\mathrm{Pd}$, and the redox properties of $\mathrm{CeO}_{2}$, which promotes the activation of water molecules and prevents carbon deposition due to its oxygen storage capacity $[7,8]$. For these reasons, in recent years $\mathrm{RhPd} / \mathrm{CeO}_{2}$ has been used successfully in a variety of catalytic reactor configurations, such as conventional packed bed reactors [9,10], honeycombs [11], membrane reactors [12-14], and microreactors [15]. RhPd bimetallic nanoparticles (NPs) anchored over a reducible support such as $\mathrm{CeO}_{2}$ constitute a complex system, where segregation of one of the metals towards the surface of the NPs, changes in the oxidation states, participation of surface oxygen atoms and hydroxyl species are all possible. In addition to fundamental understanding, getting insight into the properties of the active sites may provide important information to further optimize the catalyst formulation and/or preparation procedure. We have recently carried out an operando near-ambient pressure X-ray photoelectron spectroscopy (AP-XPS) study to monitor the surface restructuring and chemical state of unsupported model $\mathrm{Rh}_{0.5} \mathrm{Pd}_{0.5}$ nanoparticles and of the same model $\mathrm{Rh}_{0.5} \mathrm{Pd}_{0.5}$ nanoparticles supported on $\mathrm{CeO}_{2}$ powder, constituting a real catalyst, during exposure to reducing, oxidizing and ESR conditions (0.05 mbar) [16]. The catalytic performance of the model NPs supported on $\mathrm{CeO}_{2}$ proved to be much superior to that of unsupported $\mathrm{Rh}_{0.5} \mathrm{Pd}_{0.5}$ [16]. By using synchrotron radiation and changing the X-ray energy we were able to obtain valuable 
information from different depths of the NPs and we showed that the reducible ceria support played a crucial role in the catalytic process by providing new active sites strongly affecting both the physical and chemical properties of the metal NPs. The interaction of the metal NPs with the ceria support not only provided active oxygen atoms to the superficial metal atoms of the NPs, but also limited the reorganization of the metals under reaction (quenching effect) with respect to the unsupported metal NPs [16]. Simultaneously, we performed in situ XPS studies in a separate in-house system over the same samples using a conventional Al K $\alpha$ X-ray source. The term "in situ" here means that the samples were transferred between the analysis chamber and the reactor without exposing them to the atmosphere and the photoelectron spectra were recorded under ultra high vacuum. These in situ experiments are discussed here and the results are compared with those obtained under operando conditions.

\section{Experimental methods}

The preparation of the model $\mathrm{Rh}_{0.5} \mathrm{Pd}_{0.5} \mathrm{NPs}$ and the corresponding $\mathrm{Rh}_{0.5} \mathrm{Pd}_{0.5} / \mathrm{CeO}_{2}$ catalyst was reported in detail in [16]. Briefly, the model NPs were prepared by simultaneous co-complexation of $\mathrm{Rh}$ and Pd ions using PAMAM followed by a single reduction step with $\mathrm{NaBH}_{4}$ and by an extraction process with a toluene solution containing dodecanethiol. These are referred to as RhPd NPs. The $\mathrm{Rh}_{0.5} \mathrm{Pd}_{0.5} / \mathrm{CeO}_{2}$ catalyst ( 3 wt. $\% \mathrm{Rh}+\mathrm{Pd}, \mathrm{Rh}: \mathrm{Pd}=1: 1$ molar) was prepared by incipient wetness impregnation from a toluene solution containing the $\mathrm{Rh}_{0.5} \mathrm{Pd}_{0.5} \mathrm{NPs}$ over conventional $\mathrm{CeO}_{2}$ powder, which was prepared by precipitation from $\mathrm{CeCl}_{3}$ and $\mathrm{NH}_{3}$ and calcined at $823 \mathrm{~K}$. This sample is referred to as $\mathrm{RhPd} / \mathrm{CeO}_{2}$.

Scanning electron microscopy (SEM) images were recorded at $5 \mathrm{kV}$ using a Zeiss Neon40 Crossbeam Station instrument equipped with a field emission source. About two hundred particles were considered for particle size distribution estimation. High 
resolution transmission electron microscopy (HRTEM) was carried out using a JEOL 2010F electron microscope equipped with a field emission source at an accelerating voltage of $200 \mathrm{kV}$. Samples were deposited on holey carbon-coated grids. The point-topoint resolution achieved was $0.19 \mathrm{~nm}$ and the resolution between lines was $0.14 \mathrm{~nm}$. The average particle diameter was calculated from the mean diameter frequency distribution with the formula: $d=\Sigma n_{i} d_{i} / \Sigma n_{i}$, where $n_{i}$ is the number of particles with particle diameter $d_{i}$ in a certain range.

X-ray photoelectron spectroscopy (XPS) was performed on a SPECS system equipped with an Al anode XR50 source operating at $150 \mathrm{~mW}$ and a Phoibos MCD-9 detector. The pass energy of the hemispherical analyzer was set at $25 \mathrm{eV}$ and the energy step was set at $0.1 \mathrm{eV}$. The pressure in the analysis chamber was kept below $10^{-7} \mathrm{~Pa}$. The area analyzed was about $2 \mathrm{~mm} \times 2 \mathrm{~mm}$. Data processing was performed with the CasaXPS program (Casa Software Ltd., UK). Atomic fractions were calculated using peak areas normalized on the basis of acquisition parameters after background subtraction, experimental sensitivity factors and transmission factors provided by the manufacturer. In situ experiments were performed in a reaction chamber connected to the analysis chamber, which allowed for the performance of treatments at atmospheric pressure and temperatures up to $823 \mathrm{~K}$ and for transferring samples without exposing them to air. The temperature of the sample was measured with a thermocouple in contact with the sample holder, which was heated with an IR lamp. The evolution of products during the in situ experiments was followed by a mass spectrometer (Ametek Dycor, $0-100 \mathrm{amu})$. Gases $\left(20 \mathrm{~mL} \cdot \mathrm{min}^{-1}\right)$ were introduced into the reaction chamber by means of mass flow controllers (Bronkhorst). The ESR mixture was introduced by bubbling Ar through a water and ethanol solution prepared to attain a gaseous stream with a water/ethanol ratio of 6 (steam-to-carbon $\mathrm{S} / \mathrm{C}=3$ ). Al $\mathrm{K} \alpha$ photons of energy 1486.6 eV generate Rh 3d and Pd 3d photoelectrons of kinetic energies ca. $1179 \mathrm{eV}$ and ca. $1151 \mathrm{eV}$, respectively, which account for an inelastic mean free path (IMFP) of 
$1.6 \mathrm{~nm}$. The IMFP is defined as the distance travelled by an electron where the probability of escape has decayed to $1 / \mathrm{e}$ or $37 \%$. Considering that our spherical NPs were spherical and measured about $4 \mathrm{~nm}$ in diameter (see below), the volume enclosed within one IMFP from the surface inside a sphere of diameter $4 \mathrm{~nm}$ accounts for ca. $57 \%$ of the total volume of the NP. Cerium $3 d$ spectra were deconvoluted using six peaks for $\mathrm{Ce}^{4+}(\mathrm{V}, \mathrm{V}$ ', V'", U, U' and U'”) corresponding to three pairs of spin-orbit doublets and four peaks for $\mathrm{Ce}^{3+}\left(\mathrm{V}_{0}, \mathrm{~V}^{\prime}, \mathrm{U}_{0}\right.$ and $\left.\mathrm{U}^{\prime}\right)$, which correspond to two doublets, based on the peak positions reported by Mullins et al. [17], where $U$ and $V$ refer to the $3 d_{3 / 2}$ and $3 d_{5 / 2}$ spin-orbit components, respectively. Rhodium $3 d$ and Palladium $3 d$ spectra were calibrated for energy taking into account the position of the reduced component of both noble metals $\left(307.0 \mathrm{eV}\right.$ and $334.9 \mathrm{eV}$ for $\mathrm{Rh} 3 \mathrm{~d}_{5 / 2}$ and $\mathrm{Pd} 3 \mathrm{~d}_{5 / 2}$, respectively). In this study, the model RhPd NPs were deposited by drop casting the toluene solution containing the preformed RhPd NPs directly over a stainless steel sample holder. The $\mathrm{RhPd} / \mathrm{CeO}_{2}$ catalyst powder was pressed to form a self-consistent disk, which was placed on a stainless steel sample holder.

\section{Results and discussion}

\subsection{Model RhPd nanoparticles}

The sequence of in situ treatments and XPS analyses performed on the model RhPd NPs was: oxidation with air at, 1) $573 \mathrm{~K}, 2) 673 \mathrm{~K}, 3) 823 \mathrm{~K}, 4$ ) reduction with $\mathrm{H}_{2}$ at 573 $\mathrm{K}, 5$ ) ethanol steam reforming at $823 \mathrm{~K}$, and 6) reduction with $\mathrm{H}_{2}$ at $823 \mathrm{~K}$. After each of these steps, the sample was transferred to the analysis chamber where a survey spectrum and Rh 3d, Pd 3d, C 1s, S 2p spectra were recorded. As expected, during the stepwise oxidations the noble metal to carbon atomic ratios gradually increased due to the loss of the dodecanethiol protecting shell that surrounded the RhPd cores; no sulfur was detected after the oxidation at $573 \mathrm{~K}$. Figure 1 shows $\mathrm{Rh} 3 \mathrm{~d}$ and Pd $3 \mathrm{~d}$ 
spectra deconvolution for the whole sequence of treatments and Table 1 compiles the values corresponding to the reduced and oxidized species for $\mathrm{Rh}$ and $\mathrm{Pd}$ after each treatment. Rhodium 3d spectra were deconvoluted using three components, one corresponding to metallic $\mathrm{Rh}$ at $307.0 \mathrm{eV}(\mathrm{Rh}(0))$, and two oxide components at 308.2 $\mathrm{eV}$ and $309.3 \mathrm{eV}$ for $\mathrm{Rh} 3 \mathrm{~d}_{5 / 2}$, which can be formally ascribed to $\mathrm{Rh}(\mathrm{I})$ and $\mathrm{Rh}(\mathrm{III})$, respectively [18]. Three components were also used for $\mathrm{Pd} 3 \mathrm{~d}$ deconvolution: one of metallic $\mathrm{Pd}$ at $334.9 \mathrm{eV}(\mathrm{Pd}(0))$, and two oxide components at $335.8 \mathrm{eV}$ and $336.7 \mathrm{eV}$ for $\mathrm{Pd} 3 d_{5 / 2}$, which can be formally attributed to $\mathrm{Pd}(\mathrm{II})$ and $\mathrm{Pd}(\mathrm{IV})$ species, respectively [18].

From Figure 1 and Table 1 it is evident that increasing the calcination temperature resulted in the progressive growth of oxidized $\mathrm{Rh}$ and $\mathrm{Pd}$ species. The deconvolution of the $\mathrm{Pd}$ spectra adjusted well considering the contribution at $334.9 \mathrm{eV}$ corresponding to $\mathrm{Pd}(0)$ and only one oxidized component at about $336.7 \mathrm{eV}$, which corresponds to highly oxidized Pd species. In contrast, Rh spectra recorded after calcination at 573 and $673 \mathrm{~K}$ required the contribution of the three $\mathrm{Rh}(0), \mathrm{Rh}(\mathrm{I})$ and $\mathrm{Rh}(\mathrm{III})$ components, whereas after oxidation at $823 \mathrm{~K} \mathrm{Rh}$ was completely oxidized. This is in accordance with the different stability of the metal oxides at different temperatures [19]. After reduction with $\mathrm{H}_{2}$ at $573 \mathrm{~K}$ (the temperature used for activating the catalyst for the ESR [9-16]), both metals reduced, as expected, but to a different degree. In the case of Pd, the component at higher binding energies corresponding to highly oxidized $\mathrm{Pd}$ disappeared and the spectrum was adjusted with only two components at 334.9 and $335.8 \mathrm{eV}$, corresponding to $\mathrm{Pd}(0)$ and $\mathrm{Pd}(\mathrm{II})$, respectively. A similar transformation was observed in the Rh $3 \mathrm{~d}$ spectrum, where two contributions at 307.0 and $308.2 \mathrm{eV}$ were required, corresponding to $R h(0)$ and $R h(I)$ species, respectively. The reduction of $R h$ was more severe than that of $\mathrm{Pd}$ (Table 1) in accordance with their noble metal character. After ethanol steam reforming, both metallic and oxidized species were detected for both $\mathrm{Rh}$ and $\mathrm{Pd}$. The distribution between $\mathrm{Rh}(0)$ and $\mathrm{Rh}(\mathrm{I})$ was virtually 
identical to that of the activated sample, but $\mathrm{Pd}$ reduced considerably under ESR conditions with respect to the activated sample (Figure 1). Since the ESR process yields high amounts of hydrogen, an additional experiment was performed in situ by exposing the sample to $\mathrm{H}_{2}$ at the reaction temperature, $823 \mathrm{~K}$. Interestingly, both the $\mathrm{Rh} 3 \mathrm{~d}$ and $\mathrm{Pd} 3 \mathrm{~d}$ spectra remained almost unchanged, indicating that the species present in the sample were essentially governed by the presence of hydrogen at the reaction temperature.

At the end of the study, the sample was recovered and examined by SEM. Figure 2a shows a representative image of the model NPs after reaction, which were very well distributed over the sample holder and their mean size was $5 \pm 1 \mathrm{~nm}$. This compares well to the initial size of the model NPs as synthesized, which measured about $4 \pm 1 \mathrm{~nm}$ [16], and corroborates that the volume sampled by XPS from the surface inside the NPs accounted for about $57 \%$ of their total volume.

Concerning the atomic rearrangement of $\mathrm{Rh}$ and $\mathrm{Pd}$ in this sampled volume, Figure 3 shows the relative ratio of the metals after each of the treatments performed. Initially (after oxidation at $573 \mathrm{~K}$ ), the external part of the NPs was considerably enriched in Pd $(\mathrm{Pd}: \mathrm{Rh}$ atomic ratio of ca. 8:2), suggesting that the NPs were comprised by a Rh-rich core surrounded by a Pd-rich shell. Upon oxidation at higher temperatures, 673 and $823 \mathrm{~K}$, the outer part of the particles continued to be considerably Pd-rich, but there was a progressive segregation of $\mathrm{Rh}$ towards the surface. The segregation of $\mathrm{Rh}$ was particularly important after activation of the NPs by reducing them with $\mathrm{H}_{2}$ at $573 \mathrm{~K}$, where the Pd:Rh atomic ratio was ca. 6:4 in the sampled volume. After ESR at $823 \mathrm{~K}$ there was a slight segregation of Rh towards the sampled volume, which remained unaltered after reduction with pure $\mathrm{H}_{2}$ at $823 \mathrm{~K}$, providing additional evidence that the hydrogen generated during the ESR was responsible for the atomic rearrangement and oxidation states of the metals, as discussed above. 


\section{2 $\mathrm{RhPd} / \mathrm{CeO}_{2}$ catalyst}

Exactly the same treatments were conducted over the model NPs supported on $\mathrm{CeO}_{2}$. In this case, $\mathrm{Rh} 3 \mathrm{~d}, \mathrm{Pd} 3 \mathrm{~d}, \mathrm{Ce} 3 \mathrm{~d}, \mathrm{C} 1 \mathrm{~s}$, and a survey spectra were recorded after each treatment. The deconvolution of $\mathrm{Rh} 3 \mathrm{~d}$ and $\mathrm{Pd} 3 \mathrm{~d}$ XP spectra is shown in Figure 4, whereas Figure 5 shows $\mathrm{Ce} 3 \mathrm{~d}$ deconvolution. In these experiments, where the RhPd model NPs were supported on $\mathrm{CeO}_{2}$, the noble metal spectra showed new features that were not observed in the spectra of the unsupported RhPd NPs. The binding energies of $3 d_{5 / 2} P d(0)$ and $P d(I I)$ coincided with the respective photoemission lines of the unsupported RhPd NPs (334.9 and $335.9 \mathrm{eV}$ ). However, the position of the third component shifted towards higher binding energy values (337.1 vs. $336.7 \mathrm{eV}$ for the unsupported NPs), suggesting that more cationic Pd species formed in the presence of the $\mathrm{CeO}_{2}$ support. In the literature this phenomenon has been ascribed to the metalsupport interaction effect between $\mathrm{Pd}$ and $\mathrm{CeO}_{2}$ and the formation of $\mathrm{Pd}-\mathrm{O}-\mathrm{Ce}$ interactions at the $\mathrm{Pd}-\mathrm{CeO}_{2}$ interface [20]. For rhodium deconvolution, four spectral lines were needed, whereas only three were necessary for the deconvolution of the Rh $3 d$ spectra of unsupported NPs. In $\mathrm{RhPd} / \mathrm{CeO}_{2}, \mathrm{Rh} 3 \mathrm{~d}_{5 / 2}$ spectra were adjusted with components at 307.0, 307.8, 308.6 (the additional component), and $309.3 \mathrm{eV}$.

The amount of oxidized $\mathrm{Rh}$ and $\mathrm{Pd}$ in the RhPd NPs supported on $\mathrm{CeO}_{2}$ increased at higher calcination temperatures and was significantly higher than that in the unsupported model system (Table 1). This fact, together with the need for additional components in the spectra, is again indicative of metal-support interaction. In fact, $\mathrm{Rh}$ was completely oxidized and Pd contained mainly oxidized species in the sampled volume after calcination at $823 \mathrm{~K}$. After hydrogen treatment at $523 \mathrm{~K}$ (activation of the catalyst prior to ESR) the metals reduced and the components at higher binding energies for both $\mathrm{Rh}$ and $\mathrm{Pd} 3 \mathrm{~d}$ vanished, as expected (Figure 4). It is important to 
recall that the NPs supported on $\mathrm{CeO}_{2}$ were considerably more oxidized than the unsupported RhPd NPs after activation under $\mathrm{H}_{2}$ at $573 \mathrm{~K}$ (Table 1), providing additional evidence for electron withdrawal from the metals to the ceria support. This is in accordance with the Ce $3 d$ spectra (Figure 5) of the catalyst, where the amount of $\mathrm{Ce}$ (III) increased from $32 \%$ after calcination up to $43 \%$ after $\mathrm{H}_{2}$ treatment at $573 \mathrm{~K}$. Therefore, the metal NPs are less reducible when they are anchored on the ceria support, whereas they promote the reduction of $\mathrm{Ce}(\mathrm{IV})$.

After ESR at $823 \mathrm{~K}$, the catalyst further reduced, but to a much lower extent than the unsupported NPs did (Table 1). This is a remarkable result and represents an important difference between the model RhPd NPs and the $\mathrm{RhPd} / \mathrm{CeO}_{2}$ catalyst. Under ESR conditions the presence of the ceria support had a strong influence on the oxidation states of both $\mathrm{Rh}$ and $\mathrm{Pd}$. In fact, activation of the water molecules by $\mathrm{CeO}_{2}$ and formation of surface hydroxyl groups was evidenced in the operando study [16], which was considered responsible for promoting the oxidation of the metals. After reduction with pure $\mathrm{H}_{2}$ at $823 \mathrm{~K}$, both $\mathrm{Rh}$ and $\mathrm{Pd}$ further reduced, attaining values close to those recorded for unsupported $\mathrm{RhPd}$ (Table 1). This represents additional evidence that the electronic characteristics of the metals under ESR in $\mathrm{RhPd} / \mathrm{CeO}_{2}$ are strongly influenced by ceria. Interestingly, the Ce $3 \mathrm{~d}$ spectrum after ESR at $823 \mathrm{~K}$ did not show significant changes with respect to the spectrum recorded after $\mathrm{H}_{2}$ treatment at $573 \mathrm{~K}$ (45 vs. $43 \% \mathrm{Ce}(\mathrm{III})$, Figure 5), but cerium was strongly reduced after $\mathrm{H}_{2}$ treatment at $823 \mathrm{~K}(61 \% \mathrm{Ce}(\mathrm{III}))$. This suggests that hydrogen molecules likely form during ESR on the metal NPs domains and do not interact strongly with the ceria support.

At the end of the in situ XPS study the sample was removed and studied by HRTEM. A careful lattice fringe analysis was performed to identify the RhPd NPs (Figure 2b), which measured $5 \pm 1 \mathrm{~nm}$. The size of the post-reacted RhPd NPs in the $\mathrm{RhPd} / \mathrm{CeO}_{2}$ catalyst was very similar to the size found for the unsupported ones, allowing for a proper comparison of the sampled volumes by XPS. 
The relative atomic fractions of $\mathrm{Rh}$ and $\mathrm{Pd}$ for the $\mathrm{RhPd} / \mathrm{CeO}_{2}$ catalyst after each treatment are shown in Figure 3, where they are compared to that of unsupported RhPd NPs. It is important to remark that the extent of metal migration in $\mathrm{RhPd} / \mathrm{CeO}_{2}$ was almost inexistent -except for ESR- and that the $\mathrm{Pd}: \mathrm{Rh}$ atomic ratio was maintained approximately constant at $6: 4$. This can only be explained by the presence of metal-support interaction, which constrained atom mobility. The only significant atom segregation over $\mathrm{RhPd} / \mathrm{CeO}_{2}$ occurred after ESR, when $\mathrm{Rh}$ segregated towards the sampled volume and the $\mathrm{Pd}: \mathrm{Rh}$ atomic ratio was close to $1: 1$. However, after the treatment under $\mathrm{H}_{2}$ at $823 \mathrm{~K}, \mathrm{Pd}$ segregated towards the sampled volume and the $\mathrm{Pd}: \mathrm{Rh}$ atomic ratio reverted back to ca. $6: 4$, highlighting the special architecture of the catalyst under ESR. From Figure 3, the influence of the ceria support on atom mobility in the RhPd NPs becomes evident, since the variability of the $\mathrm{Pd}$ :Rh atomic ratio in $\mathrm{RhPd} / \mathrm{CeO}_{2}$ was much lower than that observed in the unsupported RhPd NPs.

\subsection{Comparison between in situ and operando XPS experiments}

As explained in the introduction, we carried out in parallel to this study operando nearambient pressure XPS experiments on the same samples [16]. By using synchrotron radiation several photon energies could be selected and information from different depths of the NPs was obtained. Here we will focus only on the information obtained at the highest photon energy used in the operando experiments, $1150 \mathrm{eV}$, which can be compared (similar sample depth) with the results obtained here in the in situ XPS experiments using a conventional Al Ka source. The other obvious differences between operando near-ambient pressure XPS (AP-XPS) and in situ XPS are pressure and temperature. In the in situ study, we first exposed the samples to a certain gas mixture at atmospheric pressure and high temperature, but the XP spectra was recorded after evacuation to UHV and cooling down to room temperature. However, the structure of 
heterogeneous catalysts is dynamic and may depend on the composition of the surrounding atmosphere and temperature. Both their surface structure and composition may be modified when the gaseous conditions change in order to adapt their electronic properties and geometry to the new environment. In fact, some structures and active phases only exist under reaction conditions and can differ from those identified under UHV conditions [21]. Here we have the opportunity to asses the validity of in situ XPS in ESR studies by comparing them with AP-XPS.

Figure 6 shows the relative atomic fractions of $\mathrm{Rh}$ and $\mathrm{Pd}$ as well as their metallic and oxidized fraction (dark and light colors, respectively) obtained by operando AP-XPS [16] and by in situ XPS (this work) under/after $\mathrm{H}_{2}$ at $573 \mathrm{~K}$, ESR at $823 \mathrm{~K}$ and $\mathrm{H}_{2}$ at 823 K over the model RhPd NPs and the $\mathrm{RhPd} / \mathrm{CeO}_{2}$ catalyst. For the unsupported $\mathrm{RhPd}$ NPs, the relative ratios of $\mathrm{Rh}$ and $\mathrm{Pd}$ are comparable in both operando AP-XPS and in situ XPS experiments for all the atmospheres tested. Also, the metallic vs. oxidized fractions of the metals are quite similar except for the ESR experiment, where the in situ XPS yields a higher fraction of metallic Rh and Pd. This could be a consequence of the complex atmosphere created around the RhPd NPs under ESR, where both oxidizing and reducing species are present, so that at near-ambient pressure the sampled volume of the NPs are more oxidized than under UHV, which is known to have a reducing character.

Concerning the $\mathrm{RhPd} / \mathrm{CeO}_{2}$ catalyst, the differences between operando AP-XPS and in situ XPS are much notable. In all the experiments the relative amount of $\mathrm{Pd}$ is much larger than that of Rh under operando AP-XPS with respect to in situ XPS. This could mean that temperature plays an important role on metal atom rearrangement in the presence of the ceria support, which can only be properly monitored in operando mode. In addition, the fraction of metallic vs. oxidized $\mathrm{Rh}$ and $\mathrm{Pd}$ measured in operando AP-XPS and in situ XPS is considerably different. Interestingly, the amount of reduced metals under $\mathrm{H}_{2}$ at $523 \mathrm{~K}$ is higher in operando AP-XPS with respect to in 
situ XPS, whereas under ESR the metals are much more oxidized in operando APXPS. The trend is therefore similar to the unsupported RhPd NPs, but the differences in oxidation states are much larger in $\mathrm{RhPd} / \mathrm{CeO}_{2}$. The disagreement between operando AP-XPS and in situ XPS experiments are much more pronounced for the $\mathrm{RhPd} / \mathrm{CeO}_{2}$ catalyst than for the unsupported RhPd NPs. This allows concluding that the $\mathrm{CeO}_{2}$ support plays a fundamental role in the reorganization and oxidation states of the metals in the NPs, which cannot be fully unveiled by in situ XPS experiments. Thus, the study of catalytic systems under operando conditions is essential to identify the active species at work during ESR, as the restructuring driven by the environment induces strong changes in their architecture.

\section{Conclusions}

The features of Rh 3d, Pd 3d and Ce 3d photoemitted electrons of unsupported model RhPd NPs and model RhPd NPs supported on cerium dioxide ( $\mathrm{RhPd} / \mathrm{CeO}_{2}$ catalyst) were studied by in situ XPS after oxidation at $573-823 \mathrm{~K}$, reduction at $573 \mathrm{~K}$ (activation of the catalyst), ethanol steam reforming $(E S R, S / C=3)$ at $823 \mathrm{~K}$, and reduction at 823 K. A clear effect of the ceria support on both the reorganization of $\mathrm{Rh}$ and $\mathrm{Pd}$ atoms within the NPs as well as on the oxidation states of the metals was evidenced with respect to the unsupported NPs. When supported on $\mathrm{CeO}_{2}, \mathrm{RhPd} \mathrm{NPs}$ were significantly more oxidized due to the metal-support interaction. Also, $\mathrm{CeO}_{2}$ inhibited atomic rearrangement under the different atmospheres tested except for ESR, where a partial segregation of Rh towards the surface of the NPs was observed. The in situ XP spectra recorded in this work at room temperature and under UHV were compared with the spectra that we acquired over the same samples under near-ambient pressure XPS (AP-XPS) in a synchrotron facility at 0.05 mbar and which were previously published. The results obtained for the unsupported RhPd NPs were similar for the in situ XPS 
and operando AP-XPS experiments. In strong contrast, the RhPd NPs supported on $\mathrm{CeO}_{2}$, constituting a real catalyst, were clearly more oxidized and enriched in Pd in the sampled volume under operando ESR conditions than in the in situ experiments, providing strong evidence for the importance of the metal-support interaction. Therefore, it is essential to use operando techniques to properly characterize supported metal catalysts for the ESR, as the restructuring driven by the reforming environment induces strong structural changes.

\section{Acknowledgments}

This work has been funded through grant MINECO ENE2012-36368. J.L. is Serra Húnter Fellow and is grateful to ICREA Academia program.

\section{References}

[1] J.L. Contreras, J. Salmones, J.A. Colín-Luna, L. Nuño, B. Quintana, I. Córdova, B. Zeifert, C. Tapia, G.A. Fuentes, Int. J. Hydrogen Energy 39 (2014) 18835-18853.

[2] M. Ni, D.Y.C. Leung, M.K.H. Leung, Int. J. Hydrogen Energy 32 (2007) 3238-3247.

[3] P.D. Vaidya, A.E. Rodrigues, Chem. Eng. J. 117 (2006) 39-49.

[4] A. Haryanto, S. Fernando, N. Murali, S. Adhikari, Energy \& Fuels 19 (2005) 20982106.

[5] J. Llorca, V. Cortés Corberán, N.J. Divins, R.O. Fraile, E. Taboada, in:, L.M. Gandía, G. Arzamendi, P.M. Diéguez (Eds.), Renewable Hydrogen Technologies, Elsevier, Amsterdam, 2013, pp. 135-169. 
[6] H. Idriss, M. Scott, J. Llorca, S. Chan, W. Chiu, P.-Y. Sheng, A. Yee, M. Blackford, S. Pas, A. Hill, F. Alamgir, R. Rettew, C. Petersburg, S. Senanayake, M. Barteau, ChemSusChem 1 (2008) 905-910.

[7] E. Aneggi, D. Wiater, C. de Leitenburg, J. Llorca, A. Trovarelli, ACS Catal. 4 (2014) $172-181$.

[8] E. Aneggi, N.J. Divins, C. de Leitenburg, J. Llorca, A. Trovarelli, J. Catal. 312 (2014) 191-194.

[9] P. Sheng, W. Chiu, A. Yee, S. Morrison, H. Idriss, Catal. Today 129 (2007) 313321.

[10] N.J. Divins, A. Casanovas, W. Xu, S.D. Senanayake, D. Wiater, A. Trovarelli, J. Llorca, Catal. Today (2015).

[11] E. López, N.J. Divins, A. Anzola, S. Schbib, D. Borio, J. Llorca, Int. J. Hydrogen Energy 38 (2013) 4418-4428.

[12] E. López, N.J. Divins, J. Llorca, Catal. Today 193 (2012) 145-150.

[13] R. Koch, E. López, N.J. Divins, M. Allué, A. Jossen, J. Riera, J. Llorca, Int. J. Hydrogen Energy 38 (2013) 5605-5615.

[14] A. Hedayati, O. Le Corre, B. Lacarrière, J. Llorca, Int. J. Hydrogen Energy 40 (2015) 3574-3581.

[15] N.J. Divins, E. López, Á. Rodríguez, D. Vega, J. Llorca, Chem. Eng. Process. Process Intensif. 64 (2013) 31-37.

[16] N.J. Divins, I. Angurell, C. Escudero, V. Pérez-Dieste, J. Llorca, Science 346 (2014) 620-623.

[17] D.R. Mullins, S.H. Overbury, D.R. Huntley, Surf. Sci. 409 (1998) 307-319. 
[18] C. Berg, S. Raaen, J. Phys. Condens. Matter 4 (1992) 8021-8028.

[19] S. Colussi, A. Trovarelli, G. Groppi, J. Llorca, Catal. Commun. 8 (2007) 12631266.

[20] K. Sun, W. Lu, M. Wang, X. Xu, Appl. Catal. A Gen. 268 (2004) 107-113.

[21] F. Tao, M. Salmeron, Science 331 (2011) 171-174. 


\section{Tables}

Table 1. Rh and Pd relative amounts and oxidation states recorded by in situ XPS on unsupported $\mathrm{RhPd}$ nanoparticles and $\mathrm{RhPd} / \mathrm{CeO}_{2}$ catalyst after several treatments. The values correspond to atomic percentages.

\begin{tabular}{|c|c|c|c|c|c|c|c|c|}
\hline \multirow{2}{*}{ Treatment } & \multicolumn{4}{|c|}{$\mathrm{RhPd}$} & \multicolumn{4}{|c|}{$\mathrm{RhPd} / \mathrm{CeO}_{2}$} \\
\hline & $\mathrm{Rd}_{\mathrm{red}}$ & $\mathrm{Rd}_{\mathrm{ox}}$ & $\mathrm{Pd}_{\text {red }}$ & $\mathrm{Pd}_{\mathrm{ox}}$ & $\mathrm{Rd}_{\mathrm{red}}$ & $\mathrm{Rd}_{\mathrm{ox}}$ & $\mathrm{Pd}_{\text {red }}$ & $\mathrm{Pd}_{\mathrm{ox}}$ \\
\hline $\mathrm{O}_{2} 573 \mathrm{~K}$ & 9 & 10 & 52 & 29 & 0 & 42 & 25 & 33 \\
\hline $\mathrm{O}_{2} 673 \mathrm{~K}$ & 3 & 18 & 35 & 44 & 0 & 41 & 24 & 35 \\
\hline $\mathrm{O}_{2} 823 \mathrm{~K}$ & 0 & 29 & 21 & 50 & 0 & 41 & 8 & 51 \\
\hline $\mathrm{H}_{2} 573 \mathrm{~K}$ & 30 & 8 & 31 & 31 & 16 & 29 & 24 & 32 \\
\hline ESR $823 \mathrm{~K}$ & 34 & 8 & 47 & 12 & 31 & 21 & 31 & 17 \\
\hline $\mathrm{H}_{2} 833 \mathrm{~K}$ & 30 & 11 & 44 & 14 & 35 & 8 & 39 & 18 \\
\hline
\end{tabular}




\section{Figure captions}

Figure 1. In situ $\mathrm{Pd} 3 \mathrm{~d}$ and $\mathrm{Rh} 3 \mathrm{~d}$ XP spectra recorded over unsupported RhPd nanoparticles after oxidation at $573-823 \mathrm{~K}$, reduction at $573 \mathrm{~K}$, ethanol steam reforming at $823 \mathrm{~K}$, and reduction at $823 \mathrm{~K}$.

Figure 2. SEM image of the unsupported RhPd nanoparticles (a) and HRTEM image of the $\mathrm{RhPd} / \mathrm{CeO}_{2}$ catalyst (b) after the in situ XPS experiments. Lattice fringes at $2.21 \AA$ correspond to the $\{111\}$ crystallographic planes of RhPd alloy.

Figure 3. Relative atomic fraction of Rh (circles) and Pd (squares) for unsupported RhPd nanoparticles (black symbols) and $\mathrm{RhPd} / \mathrm{CeO}_{2}$ catalyst (gray symbols) after oxidation at $573-823 \mathrm{~K}$, reduction at $573 \mathrm{~K}$, ethanol steam reforming at $823 \mathrm{~K}$, and reduction at $823 \mathrm{~K}$.

Figure 4. In situ Pd 3d and Rh $3 d \mathrm{XP}$ spectra recorded over the $\mathrm{RhPd} / \mathrm{CeO}_{2}$ catalyst after oxidation at $573-823 \mathrm{~K}$, reduction at $573 \mathrm{~K}$, ethanol steam reforming at $823 \mathrm{~K}$, and reduction at $823 \mathrm{~K}$.

Figure 5. In situ Ce $3 d$ spectra recorded over the $\mathrm{RhPd} / \mathrm{CeO}_{2}$ catalyst after oxidation at $573-823 \mathrm{~K}$, reduction at $573 \mathrm{~K}$, ethanol steam reforming at $823 \mathrm{~K}$, and reduction at 823 $\mathrm{K}$.

Figure 6. Relative atomic percentages of $\mathrm{Rh}$ and $\mathrm{Pd}$ measured in $\mathrm{RhPd} \mathrm{NPs}$ and $\mathrm{RhPd} / \mathrm{CeO}_{2}$ samples by operando near-ambient pressure XPS (AP-XPS) and by in situ XPS. In each column the dark and light colors correspond to the metallic and oxidized fractions, respectively. 


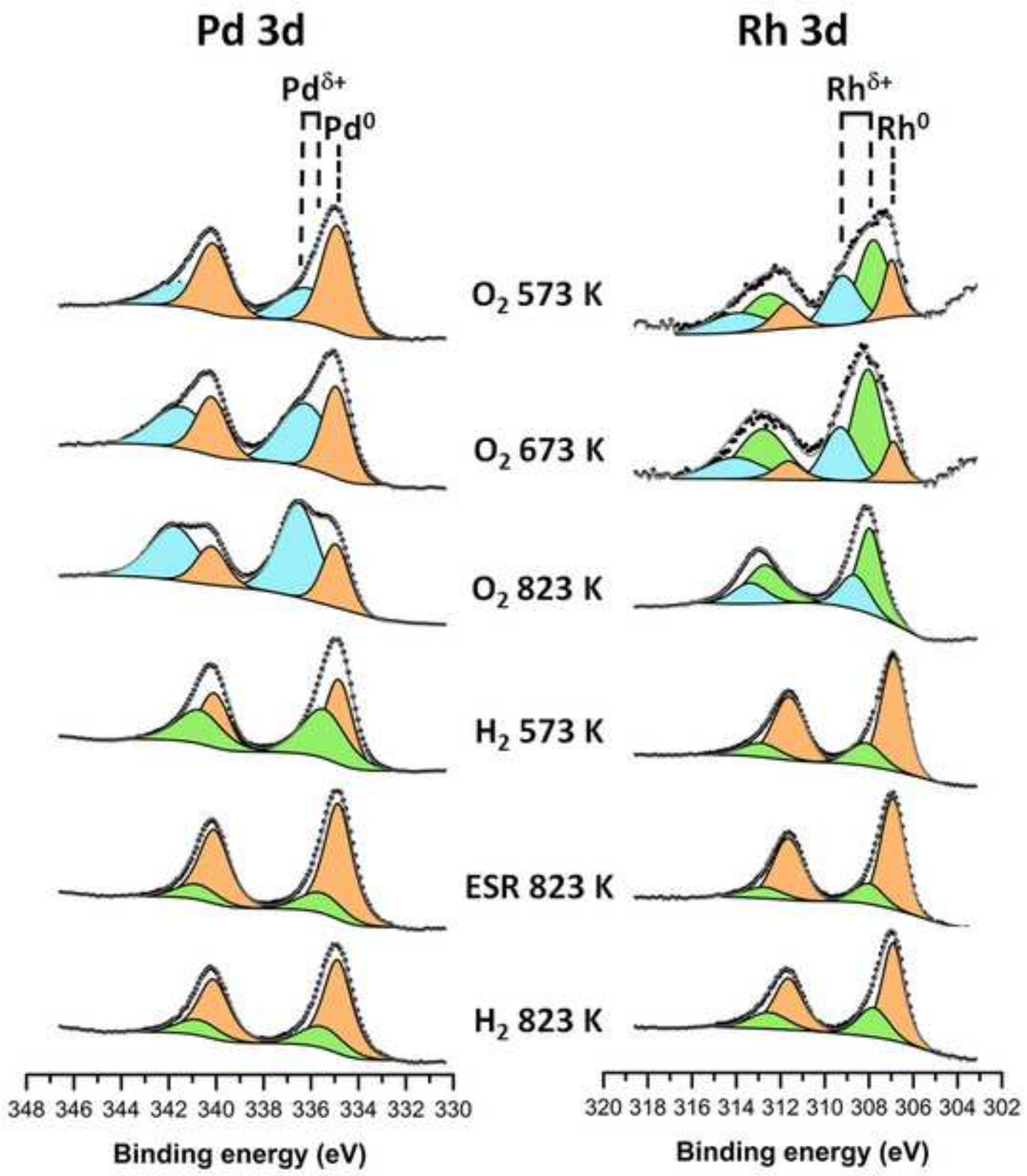

Rh 3d

$\mathrm{O}_{2} 573 \mathrm{~K}$

$\mathrm{O}_{2} 673 \mathrm{~K}$

$\mathrm{O}_{2} 823 \mathrm{~K}$

$\mathrm{H}_{2} 573 \mathrm{~K}$

ESR $823 \mathrm{~K}$

$\mathrm{H}_{2} 823 \mathrm{~K}$

Binding energy (eV) 


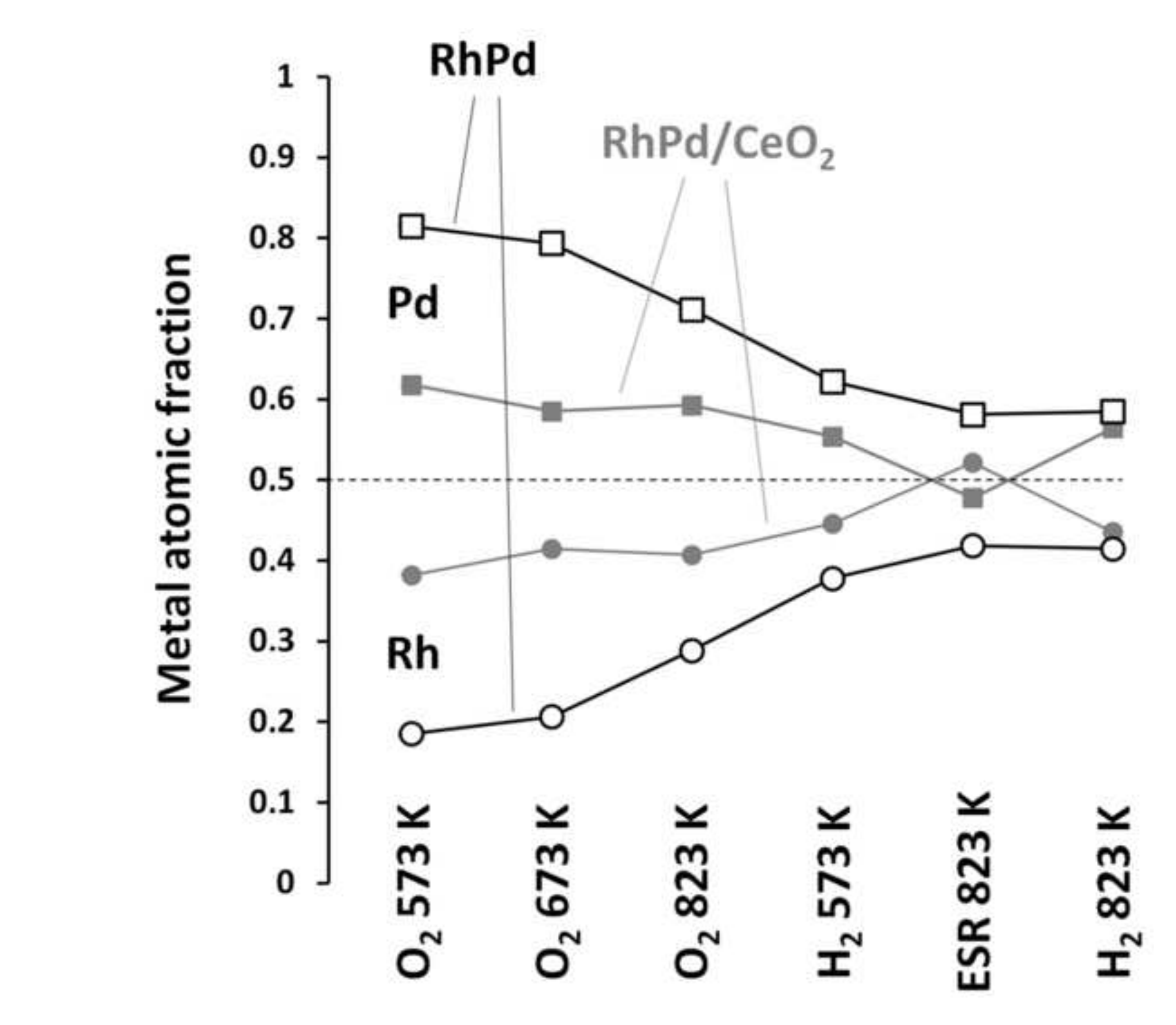

17 RhPd

.




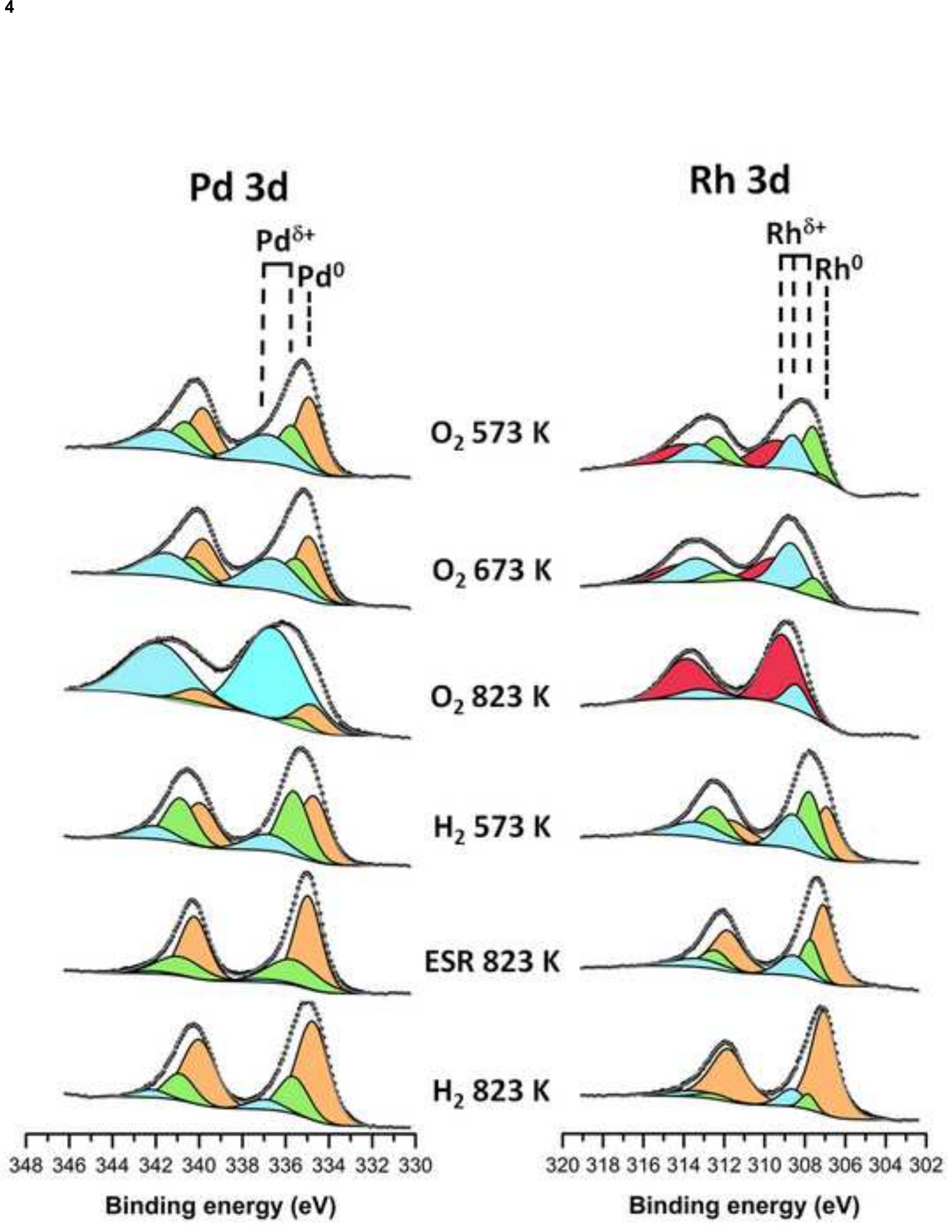

Figure 4

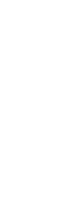

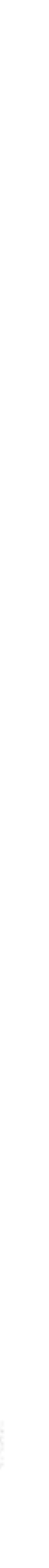

\section{Rh 3d}

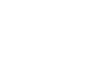

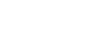

Binding energy (eV)

d

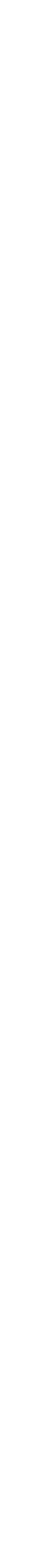

Binding energy (eV)

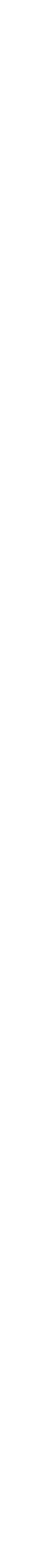

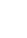

(
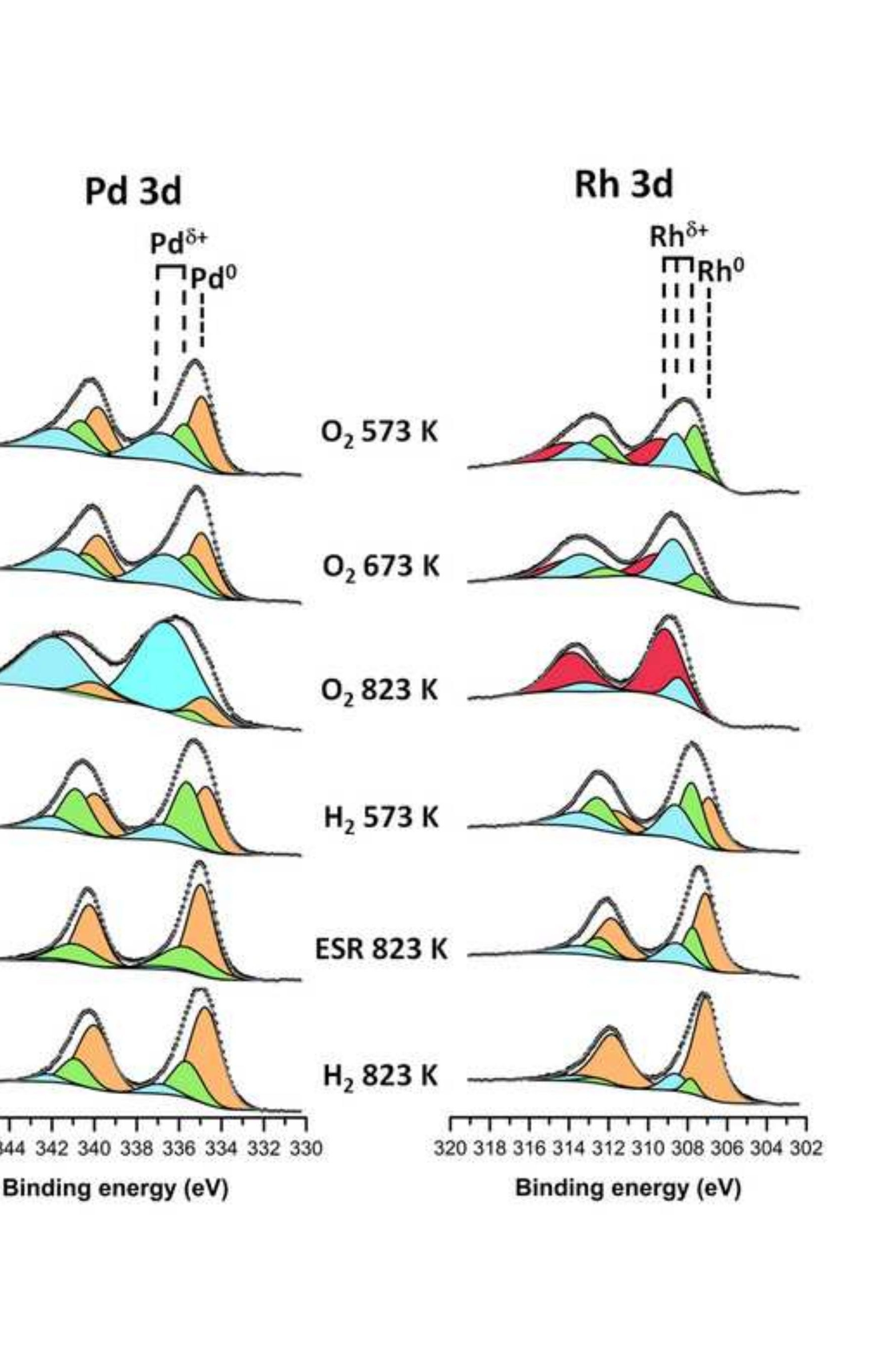


\section{Ce 3d}

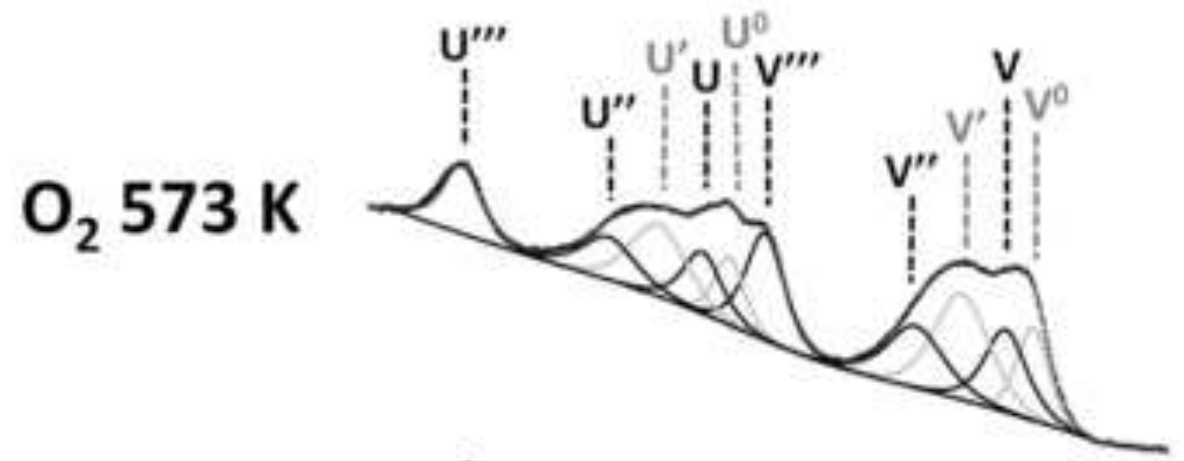

$\mathrm{O}_{2} 673 \mathrm{~K}$

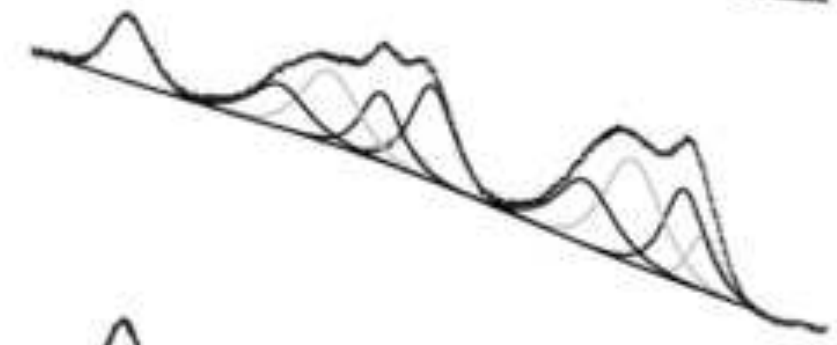

$\mathrm{O}_{2} 823 \mathrm{~K}$

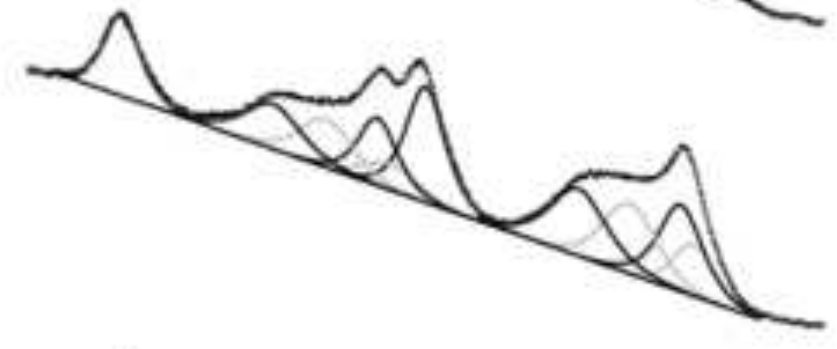

$\mathrm{H}_{2} 573 \mathrm{~K}$

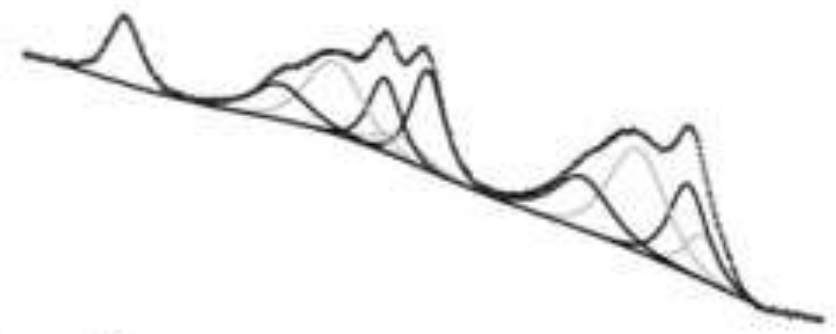

ESR $823 \mathrm{~K}$

$\mathrm{H}_{2} 823 \mathrm{~K}$
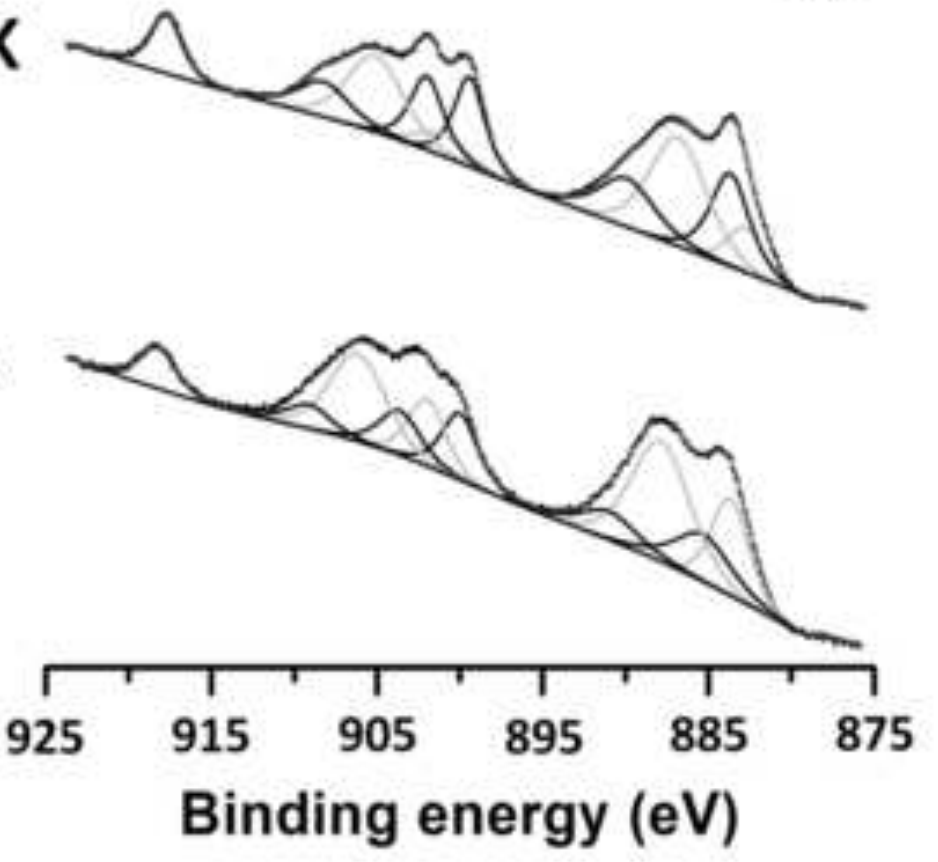


\section{RhPd}

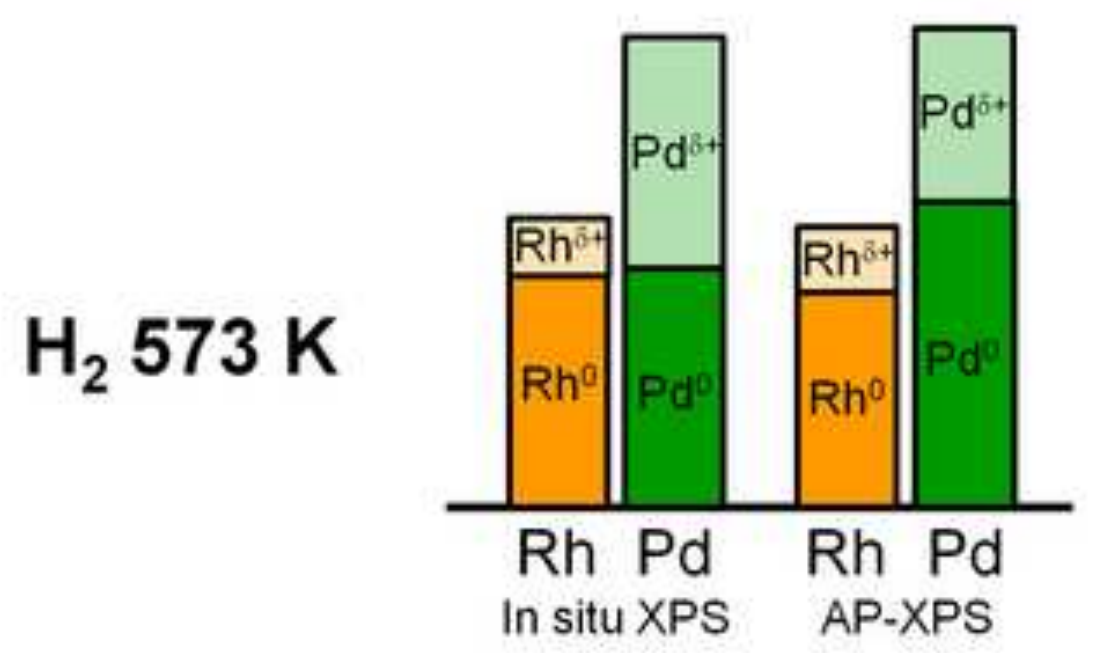

ESR $823 \mathrm{~K}$

$\mathrm{H}_{2} 823 \mathrm{~K}$

\section{$\mathrm{RhPd} / \mathrm{CeO}_{2}$}
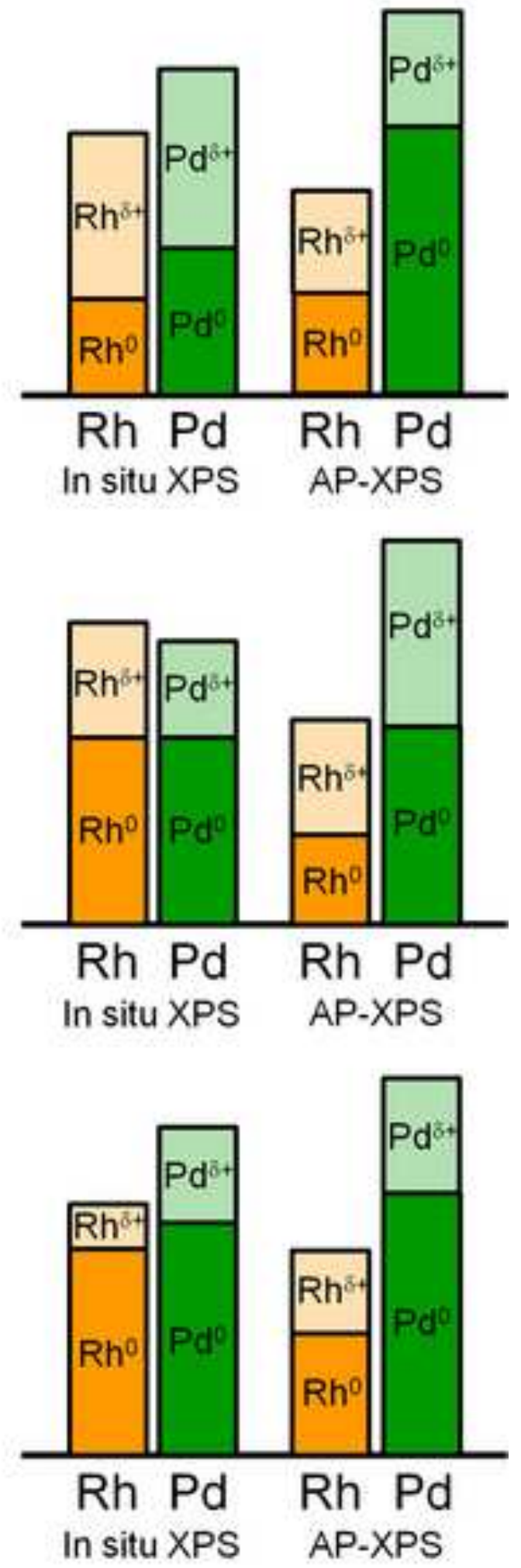